\title{
Meeting national information needs on homelessness: Partnerships in developing, collecting and reporting homelessness services statistics
}

\author{
Geoff Neideck*, Penny Siu and Alison Waters \\ Housing Homelessness and Drugs Group, Australian Institute of Health and Welfare, Canberra, Australia
}

\begin{abstract}
In 2008 the Council of Australian Governments agreed to national reforms to address homelessness through the National Agreement on Affordable Housing (NAHA) and National Partnership Agreement on Homelessness (NPAH). Integral to meeting the information needs to support these reforms was the development of a Specialist Homelessness Services data collection. Working in collaboration with Commonwealth and state and territory governments, NGO service providers, peak homelessness bodies and a private sector information systems supplier, the Australian Institute of Health and Wealth (AIHW) developed a new national data collection and introduced an innovative data collection instrument and client information management system, known as SHIP. SHIP enables NGO case workers to easily capture client information, case manage clients and monitor their progress. SHIP allows seamless collection of data conforming to national data standards and submission to AIHW each month via a secure website.

This paper describes the strong partnership arrangements that successfully delivered the new information system and data collection to 1500 NGO service providers across Australia and is providing valuable information to support measurement of policy effectiveness under the NAHA and NPAH in achieving successful outcomes for the clients of homelessness services.
\end{abstract}

Keywords: Homelessness, data collection, specialist homelessness services

\section{Introduction}

This paper presents the work of the Australian Institute of Health and Welfare (AIHW) which successfully developed and implemented a major new national data collection of homelessness services and the two key partnerships that made this possible.

The Australian Commonwealth Government in 2008 released a policy positioning 'White Paper' on the issue of homelessness entitled, The road home: a national approach to reducing homelessness [1]. The

\footnotetext{
${ }^{*}$ Corresponding author: Geoff Neideck, Head of the Housing Homelessness and Drugs Group at the Australian Institute of Health and Welfare, GPO Box 570, Canberra ACT 2601, Australia. Tel.: +61 262441000; E-mail: geoff.neideck@aihw.gov.au.
}

White Paper outlined a vision for the reduction of homelessness in Australia with a call for services towards the prevention of homelessness, alongside an increased supply of affordable and supported housing. The Council of Australian Governments (COAG) agreed to national reforms through the National Agreement on Affordable Housing (NAHA) and the National Partnership Agreement on Homelessness (NPAH) which commenced in 2008 and 2009 respectively. The Commonwealth government at the time set targets for the reduction in homelessness under the housing and homelessness reforms. The NAHA and NPAH included a number of performance indicators to measure progress towards these targets and the other objectives of the agreements.

These reforms highlighted an urgent need to improve the evidence base around homelessness, as the 
existing evidence base was insufficient to measure the policy's desired outcomes. Chief among the information improvements that were sought were:

- Enhancements to data collected on homelessness services and their clients;

- Improvements to identifying homeless people in the 5-yearly Census of Population and Housing conducted by the Australian Bureau of Statistics (ABS) and in its household surveys;

- Improvements in the income support administrative system in identifying people who were homelessness or at risk;

- Development of a longitudinal survey of people most vulnerable to homelessness; and,

- An expansion in homelessness research.

As the major national agencies reporting on housing and homelessness AIHW and ABS played a leading role in shaping the information improvements in these initiatives through expert advice to Commonwealth, State and Territory governments.

As part of the reform package AIHW was funded to develop the new homelessness services data collection and assist with national performance indicator development. In order to provide information that could be used to assess progress against the national agreements each of these initiatives required implementation within relatively short timeframes.

\section{Homelessness population measures and services statistics internationally}

Homelessness presents significant social and economic problems to many countries across the world. Statistics on the prevalence of homeless are important to governments in understanding the extent of the problem and in planning responses to assist those who have become homeless or face an imminent prospect of losing their housing. Similarly, many governments are interested in measuring the population of homeless people who are provided with services, in order to understand the demand for services and the types of assistance that is needed.

By its nature homelessness in the general population is difficult to measure. Traditional methods of obtaining population estimates come through censuses or surveys of households that are identified as residing in established dwellings with stable household arrangements. People living on the street or in unconventional or improvised dwellings are difficult for surveyors to enumerate. Similarly, the stability or security of many people's accommodation arrangements (e.g. couch surfers, precarious tenure) may be difficult to identify.

Notwithstanding these constraints, a number of countries produce estimates of the homeless population from population censuses. Australia [2], US [3] and Ireland [4] use mixed approaches by enumerating people in crisis accommodation and other shelter facilities for homeless people, along with "street counts" of locations known to be used by rough sleepers. These latter counts, generally involve partnerships of statistics agencies with homeless service providers. A number of countries provide estimates of homeless people based on one-off surveys of homeless services, for example, Italy's first national survey of homelessness focussed on homeless people who used free or subsidised food services, or who used emergency shelters at least once, over a period of a month in 2011 [5], or through periodic street counts of rough sleepers conducted in some areas such as street counts in London [6], Paris [7] and Dublin [8].

Estimates of sub-populations of homeless persons who are provided assistance are obtained by a number of countries through direct surveys of service providers or from the administrative systems of those providers. For example, Sweden's National Board of Health and Welfare collates snapshot data collected from municipalities, authorities, institutions and NGOs [9]. One sophisticated service usage system is the Dublin Region Homeless Executive's Pathway Accommodation and Support System - a shared homeless client database that is used by all funded homeless service providers in Dublin which is being rolled out nationally [10]. This system has many similarities to that used in Australia underpinned by a collaborative arrangement between the national data agency and the homelessness NGO sector.

\section{A note on homelessness definitions}

Homelessness has many causes, including the shortage of affordable housing, domestic and family violence, long term unemployment, mental health issues, substance abuse and family and relationship breakdown [11].

Currently, there is no agreed international definition of homelessness. Different definitions of homelessness are adopted depending on the nature of homeless populations in particular countries. The UN Statistical Division notes that this variation stems from different cul- 
tural understandings of homelessness based on concepts such as "adequate housing", "minimum community housing standard", or "security of tenure" which can be perceived in different ways by different communities [12]. A relatively narrow definition is recommended by the United Nations, as "those households without a shelter that would fall within the scope of living quarters. They carry their few possessions with them, sleeping in the streets, in doorways or on piers, or in any other space, on a more or less random basis" [13].

In Australia, official statistics reflect a broader understanding of homelessness as 'home'lessness rather than just 'rooflessness'. The Australian definition is centred around three elements: adequacy of the dwelling, security of tenure in the dwelling, and control of, and access to space for social relations [14]. Prevalence estimates gathered through the Census of Population and Housing reflects persons:

- Living in improvised dwellings, tents, sleepers out

- In supported accommodation for the homeless

- Staying temporarily with other households

- Living in boarding houses

- In other temporary lodging

- Living in 'severely' crowded dwellings [15].

Similar definitions are applied in a number of other countries. For example, both the European Typology of Homelessness and Housing Exclusion (ETHOS) [16] and Canadian definition of homelessness reflect similar categories to the Australian definition; however of particular note is that they both include people in institutions such as prisons and detention centres [17]. The current United States of America's Department of Housing and Urban Development definition is also similar to the Australian definition; however a particular area of divergence is the exclusion of people in programs targeting victims of domestic violence [18].

\section{Transition to a new homelessness services data collection in Australia}

AIHW has collected and reported homelessness data under various intergovernmental agreements since 1995. The predecessor to the newly developed data collection was the Supported Accommodation Assistance Program National Data Collection (SAAP NDC). Homeless services under the SAAP program were delivered primarily by Non-Government Organisations (NGOs).
Using an in-house data collection tool provided at no cost by AIHW, the SAAP NDC collected information from participating NGOs. The original data collection tool was developed as a software application was loaded into the service provider's own computing environment. This software enabled service providers to store information about their clients and extract data files to be sent to AIHW via a secure email service. For many NGOs this data collection tool became the primary mechanism for capturing and managing their client information, including client case notes.

The data collection developed to replace the SAAP NDC is the Specialist Homelessness Services Collection (SHSC), which commenced in July 2011. To address the information requirements of the homelessness reforms, the SHSC was designed to assist policymakers in developing initiatives to address homelessness, to monitor and improve service delivery and to better understand the outcomes for clients that were assisted. As depicted in the SHSC data model (Fig. 1) the SHSC identifies the needs of people who are homeless or at risk of becoming homeless who seek assistance from government funded homeless services. It further describes the characteristics of the client population and their housing circumstances before, during and after support. With policy priority focussed on the outcomes for individuals and families, this necessitated a change in counting units from episodes of support (as measured in the SAAP NDC) to persons. When considered with the services that are provided to these people, policy makers are able to target homelessness programs and assess which service approaches are most effective.

\section{Building strong partnerships for the provision of homelessness data}

Developing the new data collection required AIHW to work with a wide range of stakeholders - Commonwealth and State and Territory departments and agencies, NGO service providers, homelessness sector peak bodies and private sector suppliers. Through these collaborative relationships, the AIHW was able to meet the emerging information needs to support strategic homelessness reforms and ensure the continuity of information supply from homelessness service providers.

The successful development and implementation of the SHSC however, was hallmarked by two key partnerships - the first between the AIHW and the Com- 


\begin{tabular}{|c|c|c|}
\hline Clients & Services & Outcomes \\
\hline $\begin{array}{l}\text { Who is seeking } \\
\text { services? }\end{array}$ & $\begin{array}{c}\text { What assistance } \\
\text { is provided? }\end{array}$ & $\begin{array}{c}\text { What were the outcomes } \\
\text { for clients? }\end{array}$ \\
\hline Demographics & Client needs & Housing status \\
\hline Housing status & $\begin{array}{l}\text { Accommodation } \\
\text { Special needs }\end{array}$ & $\begin{array}{c}\text { Employment } \\
\text { Education/training }\end{array}$ \\
\hline $\begin{array}{c}\text { Employment } \\
\text { Education/training }\end{array}$ & Other services & Income \\
\hline Income & Referrals & $\begin{array}{c}\text { Repeat } \\
\text { homelessness }\end{array}$ \\
\hline Homelessness history & Unmet needs & \\
\hline
\end{tabular}

Fig. 1. SHSC data model.

monwealth Government and State and Territory governments and the second between the AIHW and the private sector supplier of the information management solution.

\subsection{Partnership between AIHW and governments}

The AIHW is a statutory agency within the Commonwealth Government, established by legislative authority to provide independent collection and reporting of data on health and welfare in Australia. This is done primarily using administrative data sources from the Australian States and Territories, governed through information agreements and committee structures which set the agenda for data development and national reporting based on current policy requirements.

The standard model for data provision under these arrangements is for states and territories to collate data according to agreed national data standards and supply this data (usually annually) to AIHW to undertake national reporting through its own publications and collating for other national agencies' reporting requirements. The collection of homelessness services data varies in an important respect from this model. Seven out of eight State and Territory governments collectively sought that AIHW undertake the data collection on their behalf. Under this arrangement, rather than AIHW receiving the data after it has been collected and validated, AIHW undertakes the data collection and processing directly from service providers. This partnership arrangement has two major benefits:

- Superior quality data due to consistent methods of data collection from the information source and consistent application of data validation processes, and
- Economies achieved through centralised processing resulting in lower costs.

A drawback for some jurisdictions however has been an inability to integrate SHS client data with other service information systems, particularly their housing assistance systems, and some limitations on detailed client analysis for policy and program evaluation and development. However, these drawbacks have been mitigated to some extent by making available confidentialised client level data.

\subsection{Partnership between AIHW and the private sector}

The second key partnership arose from the need for AIHW to source a client information management solution for NGOs participating in the SHSC. As AIHW developed plans to replace the SAAP NDC with a new data collection, it became apparent that the existing data collection tool, with its client information management functionality, had become integral to the operations of many NGOs. However, it could not be used with the new data collection and without a client information management system for the homelessness services, the data could not be collected as originally envisioned.

AIHW identified this gap and the potential for it to derail the proposed data collection. It successfully persuaded all parties of the need for the new data collection to be supported by a suitable replacement for the client management system. AIHW was subsequently engaged by state and territory governments to supply a replacement client management system. 
Through a government tender process, AIHW was able to identify a private sector information systems company which could develop a customised client management system that could also act as a data collection tool for the monthly homelessness data collection. This company was experienced in dealing with community sector service providers. It has a strong social justice focus and aims to strengthen communities and community organisations through information technology and undertakes a range of digital inclusion projects with government, private sector and community organisations.

AIHW developed the business and functionality specifications in consultation with state and territory governments to ensure the desired business requirements would be met by the solution. The new client information system was developed and launched as the Specialist Homelessness Information Platform (SHIP). The SHIP system provided service agency workers with the ability to better monitor client outcomes by delivering a tool that allowed better case management and provision of real-time reports to assist in identifying client needs.

The SHIP client management system allows seamless reporting of SHS national data standards for national reporting. To ensure a national data standard on official homelessness statistics was used throughout Australia by state and territory governments and applied consistently across 1,500 NGO agencies, AIHW worked with jurisdiction representatives and advisors from the homelessness sector to develop national data standards. These were developed through the AIHW web-based metadata online registry (METeOR). METeOR is used for the development, registration and dissemination of metadata for national data standards in health and welfare.

SHIP not only collects national data but provides performance monitoring and essential client case management, integral to the day to day operations of over 1,200 service agencies. SHIP is both a data collection tool and a method for homelessness service agencies to manage their client information, to utilise case management benefits and to monitor outcomes for clients in crisis.

To submit data from SHIP for the SHSC, an agency worker is only a few clicks of a button away to extract data from SHIP. They then logon to a secure AIHW web portal known as the Specialist Homelessness Online Reporting (SHOR) system to upload their agency monthly SHSC data. Figure 2 describes the data flows and functions associated with the SHSC:

\section{Key outcomes of the SHSC}

The SHSC has now been collecting homelessness services statistics for over three years and providing valuable information for policy makers and the general public about services provided to people who were homeless or at risk of homelessness.

Furthermore, the cost effectiveness, value for money and benefits of the provision of the SHIP client information system to SHS homelessness service agencies has been demonstrated over the past 3 years since its inception with smooth operational management of the SHS data collection. Participation in the SHSC is high with well over $90 \%$ of national agencies consistently returning data from SHIP to SHOR for all monthly reporting periods since the inception of the collection.

The AIHW continues in partnership with state and territory government departments in managing relationships with homelessness agencies and through intensive follow-up phases encouraging them to submit their data extracts for reporting purposes. This has a significant impact upon increasing participation and submission rates.

\subsection{Improved evidence base - spotlight on Australian SHSC results}

AIHW's publication Specialist Homelessness Services 2012-13 [19] show that in that year, 244,000 clients who were homeless or at risk of homelessness were assisted by specialist homelessness services. Over time, service provision appears to be steadily increasing, with a six per cent increase from the previous year of almost 230,000 clients that were assisted by specialist homelessness service agencies. More than half of all clients were at risk of homelessness (54\%) when they first began receiving support. Of those who were homeless when presenting to the service $(46 \%)$, $22 \%$ had no shelter or were staying in improvised dwellings and $35 \%$ were in short-term emergency accommodation.

Most clients were female (59\%). However, males were more likely to be homeless when they first received support, including being more likely to be living in a shelter or in an improvised dwelling $(28 \%$ of homeless males compared to $16 \%$ of homeless females).

Indigenous Australian's are over-represented. Although Aboriginal and Torres Strait Islander peoples represent three per cent of the total Australian pop- 


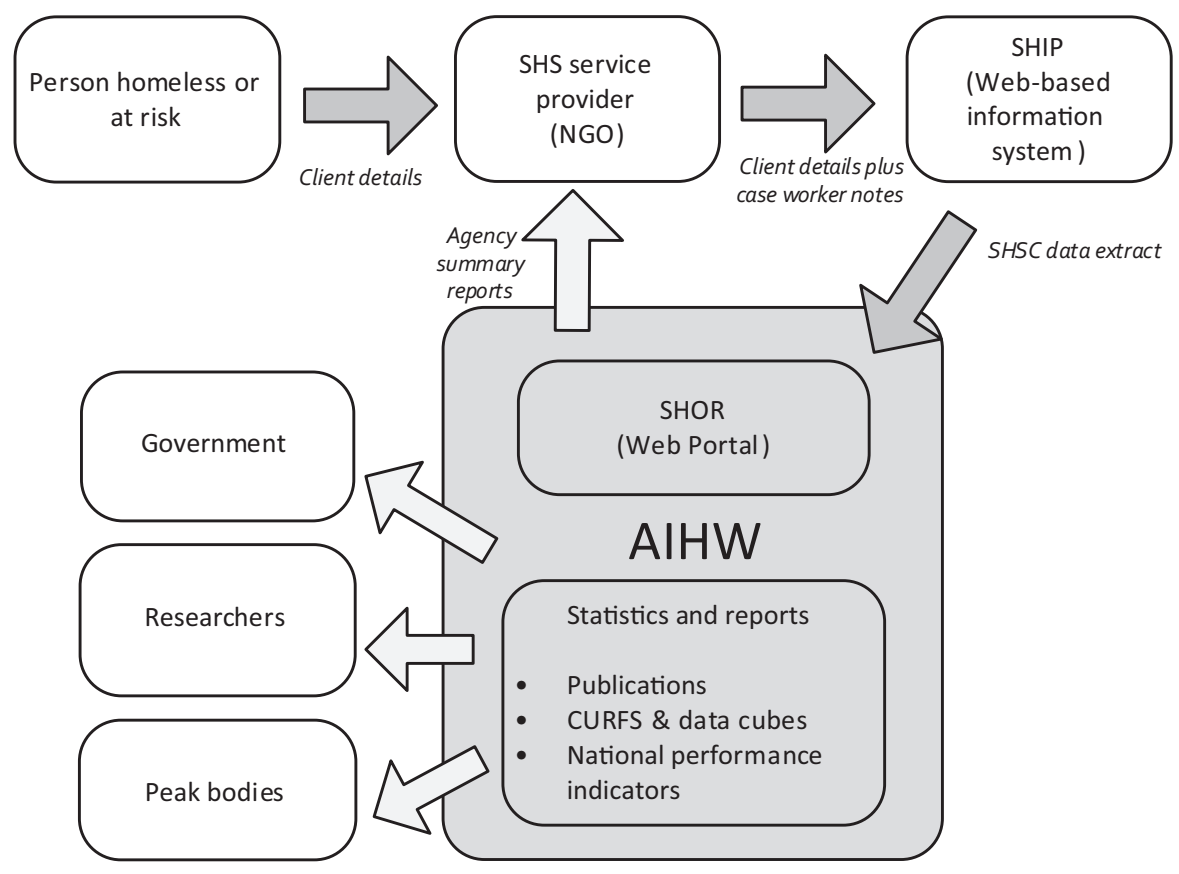

Fig. 2. SHSC data flow.

ulation, Indigenous Australians represented $22 \%$ of clients seeking specialist homelessness services.

Not surprisingly, domestic and family violence remains a leading cause of homelessness. $32 \%$ of all clients receiving assistance were escaping domestic or family violence. The majority of these were females $(63 \%)$ and $19 \%$ were children under 10 years of age.

Data from the collection has supported several key performance indicators under the national agreements.

\subsection{Agency satisfaction with the system}

To give agencies the opportunity to provide feedback to AIHW on the SHIP client management system, the AIHW conducted a user satisfaction survey in 2013. The survey sought to measure user satisfaction with SHIP as both a data collection tool and a method to manage their client information and case management. The survey was distributed to approximately 1,000 service provider agencies and over 2,000 individuals working in Specialist Homelessness Service agencies responded.

The results of the 2013 SHIP satisfaction survey demonstrate a high level of satisfaction with SHIP. Some $78 \%$ of all respondents agreed that SHIP is an effective way to collect SHS data and three-quarters agreed that they are satisfied with the system. The categories of users who were less satisfied with the sys- tem include less frequent users and those responsible for inputting a lot of data. Any negative comments received generally indicated dissatisfaction with the administrative burden of data collection in general rather than the new collection system.

When asked about the effectiveness of SHIP based upon the type of use, overall respondents rated SHIP highly. The respondents who used SHIP both to enter data and for client management had a satisfaction rate of $82 \%$. Those who used it for reporting purposes and/or to run SHS data extracts rated its effectiveness even higher $(83 \%)$.

The users who found SHIP less effective were new users (59\%) and those who only used SHIP to enter data for the SHS collection rather than for client management (62\%). The latter category of users may be more dissatisfied as a result of the burden of data collection, relative to the benefits gained for the user. Interestingly, over half $(56 \%)$ of the respondents agreed with the statement that "SHIP has improved the way our agency operates".

The responses from agencies supplied a rich source of information to AIHW and their state and territory government partners to better understand the levels of satisfaction with SHIP. Positive feedback has been received regularly by AIHW from users of SHIP about how effectively SHIP enables agencies to capture and manage client information, to utilise case management 
benefits and to monitor outcomes for clients. Information from this survey supplies additional quantitative evidence that supports the observations and anecdotal feedback from the sector.

\section{Concluding remarks}

AIHW builds collaborative relationships within national committees and networks to develop, collect and report data. AIHW also draws on the skills and expertise available in the private sector where appropriate, in delivering its functions. This allows AIHW to develop evidence and provide official homelessness statistics to contribute to national policy and decision making. It would not be possible to produce authoritative and comparable statistics on national homelessness services without the strong partnerships of Commonwealth and state and territory governments both through funding and in using agreed standards and definitions for homelessness national minimum data sets and the data collection.

In introducing a new homelessness services data collection for Australia, two important partnerships have shaped a successful result. The outcomes achieved from these partnerships have been:

1. Securing the continued supply of high quality data to support policy needs and report to governments and the community on progress in addressing homelessness;

2. Development of a more relevant and richer evidence base on homelessness services;

3. Ensuring business continuity in client information management at minimal cost for many NGOs providing homelessness services.

These outcomes reflect a number of success factors for data agencies in delivering reliable statistics. These include:

- Maintaining the independence of the data agency in providing objective advice and reporting in meeting the nation's information needs.

- Working closely with policy makers from the early stages and throughout the process, to ensure that data is fit for purpose.

- Engaging at arm's length with private sector suppliers while drawing on their expertise.

- Embedding data collection in the data provider's business processes.

In addition, AIHW's ability to report national homelessness services statistics is made possible through its cultivation of strong partnerships with homelessness service agencies. These agencies and their dedicated workers provide the administrative data each month by using a certified information system incorporating national homelessness statistical standards.

SHS data provide an official measure of the service response directed to those experiencing housing difficulty. While the data does not provide a full measure of the extent of homelessness in Australia, the SHSC data on emergency and supported accommodation do contribute high quality official statistics on the profile of homelessness in Australia.

\section{Acknowledgements}

The Australian Institute of Health and Welfare is grateful to the Australian Government Department of Social Services and the state and territory departments responsible for the delivery of specialist homelessness services for funding the Specialist Homelessness Services Collection and for working with us to conduct the data collection.

We are especially grateful to all homelessness service agencies and their clients for their participation in the data collection to enhance the value of official homelessness statistics.

\section{References}

[1] Department of Families, Housing and Community Services and Indigenous Affairs, The Road Home: A National Approach to Reducing Homelessness. Commonwealth of Australia, Australia, 2008.

[2] Australian Bureau of Statistics, Information paper - Methodology for Estimating Homelessness from the Census of Population and Housing. Cat.no. 2049.0.55.001, Canberra, 2012.

[3] The U.S. Department of Housing and Urban Development, The 2014 Annual Homeless Assessment Report (AHAR) to Congress: Part 1 Point-in-Time Estimates of Homelessness. Oct 2014. <https://www.hudexchange.info/resources/docu ments/2014-AHAR-Part1.pdf>. Accessed 6 January 2015.

[4] European Observatory on Homelessness, Extent and Profile of Homelessness in European Member States: A Statistical Update 4. Brussels, 2014. <http://www.feantsaresearch. org/IMG/pdf/feantsa-studies_04-web2.pdf>. Accessed 9 January 2015.

[5] ibid.

[6] Department for Communities and Local Government, Evaluating the Extent of Rough Sleeping: A New Approach. London, 2010. <https://www.gov.uk/government/uploads/system/ uploads/attachment_data/file/6009/1713784.pdf>. Accessed 6 January 2015.

[7] The Economist, Homeless in France: Down and out in Paris. Paris, 2012. <http://www.economist.com/node/21564608>. Accessed 6 January 2015. 
[8] Dublin City Council, Official Street Count figures on rough sleeping for Winter 2014 across the Dublin Region. Dublin City Council, 2014. <http://www.dublincity.ie/official-streetcount-figures-rough-sleeping-winter-2014-across-dublinregion>. Accessed 6 January 2015.

[9] Socialstyrelsen, Homelessness in Sweden 2011. The National Board of Health and Welfare, 2011. <http://www.socialsty relsen.se/publikationer2012/homelessnessinsweden2011>. Accessed 9 January 2015.

[10] I. Baptista, Homelessness Policies in Dublin Meeting Report. HABITACT Peer Review 2013. Dublin City, 4-5 April 2013. $<$ http://www.habitact.eu/files/activity/peerreview/_discussion paper_dublin2013.pdf> Accessed 9 January 2015.

[11] Department of Families, Housing and Community Services and Indigenous Affairs, Op Cit.

[12] Department of Economics and Social Affairs Statistics Division, Principles and Recommendations for Populations and Housing Censuses: Revision 2. United Nations, New York, 2008, paragraph 1.452. <http://unstats.un.org/unsd/publicati on/seriesM/seriesm_67Rev2e.pdf $>$. Accessed 6 January 2015.

[13] Department of Economics and Social Affairs Statistics Division, United Nations Demographic Yearbook review: National reporting of household characteristics, living arrangements and homeless households. United Nations, 14 April
2004, p.23. <http://unstats.un.org/unsd/demographic/produc ts/dyb/techreport/hhChar.pdf>. Accessed 6 January 2015.

[14] Australian Bureau of Statistics, Information paper - A statistical definition of homelessness. Cat.no. 4922.0, Canberra, 2012.

[15] Australian Bureau of Statistics, Information paper - Methodology for Estimating Homelessness from the Census of Population and Housing. Cat.no. 2049.0.55.001, Canberra, 2012.

[16] Edgar, B and Meert, H, Fourth review of statistics on homelessness in Europe: The ETHOS definition of homelessness. FEANTSA, Nov 2005. <http://feantsaresearch.org/ IMG/pdf/2005_fourth_review_of_statistics.pdf>. Accessed 6 January 2015.

[17] Canadian Homelessness Research Network, Canadian Definition of Homelessness. Homeless Hub, 2002. <www.home lesshub.ca/CHRNhomelessdefinition/>. Accessed 6 January 2015.

[18] The U.S. Department of Housing and Urban Development, Annual Homeless Assessment Report (AHAR): Frequently Asked Questions. Oct 2014. <https://www.hudexchange.info/ resources/documents/2014-AHAR-Frequently-AskedQuestions.pdf>. Accessed 6 January 2015.

[19] Australian Institute of Health and Welfare, Specialist Homelessness Services 2012-13. Cat.no. HOU 273. Canberra, 2013. 